\title{
Recent Technological and Economic Change among Industrialized Countries: Insights from Population Growth*
}

December 2001, revised February 2003

\author{
Paul Beaudry \\ Department of Economics \\ University of British Columbia \\ 997-1873 East Mall \\ Vancouver, B.C. \\ Canada, V6T 1 Z1 \\ and NBER. \\ paulbe@interchange.ubc.ca
}

\author{
Fabrice Collard \\ CNRS-GREMAQ and IDEI \\ Université de Toulouse I \\ Manufacture des tabacs, bâtiment F \\ 21 allée de Brienne \\ 31000 Toulouse \\ France \\ fabrice.collard@univ-tlse1.fr
}

\begin{abstract}
We use cross-country observations on the effects of population growth to show why differences in rates of growth in working age population may be a key to understanding differences in economic performance across industrialized countries over the period 1975-97 versus 1960-74. In particular, we argue that countries with lower rates of adult population growth have adopted new capital intensive technologies more quickly than their high population growth counterparts, therefore allowing them to reduce their work-time without deteriorating growth in output-per-adult.
\end{abstract}

Key Words: Human and Physical Capital Accumulation, Technological Adoption, Population growth

JEL Class.: O33, O41.

\footnotetext{
*This paper was started while Beaudry was visiting GREMAQ, Toulouse. We want to thank Franck Portier, Javier Ortega and Gilles Saint-Paul for early discussions.
} 


\section{Introduction}

Economic performance among industrialized countries over the last decades of the twentieth century has been puzzling on several dimensions. In particular, economic outcomes between this set of countries have differed considerably over this period, both in terms of output-per-worker and employment rates, even though it seems most likely that the same technological forces have affected all of them. It is therefore natural to ask why this diversity has come about? The object of the paper is to argue that differences in the rate of growth of the working age population -which we will refer to as the adult population - may be a key to understanding this puzzle. In particular, we will show how focusing on effects of differential rates of adult population growth across industrialized countries can give insight with respect to both the nature of the recent technological change and to the reasons why countries have adjusted differently to this change.

The first part of this paper motivates our analysis by presenting a series of cross-country regressions which relate different measures of economic performance among industrialized countries to rates of adult population growth (individuals aged between 15 and 64). As we will show, there has been a rather drastic change in nature of such relationships over the period 1975-97 versus the period 1960-1974. In particular, over the earlier period (196074), the data do not indicate any systematic links between adult population growth and the growth of either output-per-adult, output-per-worker or employment-per-adult. This finding is rather unsurprising and consistent with common perceptions. However, there has been a radical change over the more recent period. In effect, over the period 1975-97, we find that adult 
population growth has exhibited a very large and systematic correlation with economic performance. For example, we show that countries with lower rates of adult population growth had much better growth performance in outputper-worker than high population growth countries, a lower performance in employment-per-adult and similar performance in output-per-adult. Moreover, we show that these results are not due to changes in the age structure of the population, but instead appear to be driven primarily by differences in the rate of growth of the adult population.

Our approach in the main body of the paper is to illustrate why these crosscountry observations are suggestive of a major technological change which favors accumulable factors. To this end, we extend a Solow-type growth model in two directions. First, we introduce the possibility of a radical technological change in the form of the arrival and the dissemination of an alternative means of production. This type of technological change is meant to capture ideas emphasized in the General Purpose Technology (GPT) literature (see e.g. Bresnahan and Trajtenberg (1995)), whereby large technological changes are viewed as offering an entirely new means of producing goods as opposed to coming simply in the form of labor augmenting technological change. Secondly, we endow households with neo-classical preferences between consumption and leisure (as in the business cycle literature) in order examine whether such structure of preferences can reconcile the observed differential behavior of output-per-adult versus output-per-worker - and hence, employment-per-adult — over the recent period.

Using this model, we show why countries with different rates of adult population growth are likely to adjust differently to a common technological change, in terms of both output-per-worker and employment-per-adult. A 
central aspect of the paper is to show that our model can both explain the qualitative features of the data, and quantitatively replicate the observed changes in importance of adult population growth in the cross-country regressions. For example, we illustrate how radical technological change can generate cross-country differences in the growth of employment-per-adult and output-per-worker of the order observed in the data. Overall, we argue that our model provides an explanation to the differential economic experiences of industrialized countries since the mid-seventies which is based on demographic factors as opposed to the more common explanation based on institutional factors.

The remaining of the paper is organized as follows. In section 2, we discuss a series of cross-country regressions linking measures of economic performance to population growth. In section 3, we present a simple growth model where we allow technological change to arrive in both the form labor augmenting progress and in the form of increased access to a alternative means of producing goods. In section 4, we derive the main theoretical implications of the model. In particular, we show why the increased access to a more capital intensive production process can cause economic outcomes across countries to differ simply due to differences in their rates of growth in the working age population. We then document the extent to which our model is capable of quantitatively replicating the data. Finally, a last section offers concluding comments. 


\section{Economic Performance and Population Growth: Some Intriguing Observations}

In this section, we report a set of cross-country regression relating three measures of economic performance - growth in output-per-adult, growth in output-per-worker and the change in employment-per-adult - to the rate of growth of the adult population and other controls. We focus exclusively on the experiences of the richest industrialized countries (countries with peradult-income in 1985 above 10,000 US\$) since it is the set of countries for which assuming common access to technological opportunities appears most plausible. The 18 countries forming our sample are Australia, Austria, Belgium, Canada, Denmark, Finland, France, Germany, Iceland, Italy, Japan, Netherlands, New-Zealand, Norway, Sweden, Switzerland, United Kingdom and the United States. ${ }^{1}$ The data are taken from OECD statistical compendium 1999 unless indicated otherwise.

The main observation that we want to emphasize in these data is that the relationships between economic performance and adult population growth has changed quite drastically over the period 1975-1997 relative to the period 1960-74, and that the change is surprising both in size and direction. In particular, over the period 1975-97, we find a systematic and large effect of adult population growth on output-per-worker and workers-per-adult that was not apparent in the earlier period..$^{2}$ In contrast, we find that the behavior of output-per-adult has been more stable.

\footnotetext{
${ }^{1}$ It is quite natural to cut the sample of countries at the level of 10,000 US $\$$ since in 1985 this is precisely where there is a large break in the data. For example, the next richest countries have per adult incomes below 7,500US $\$$.

${ }^{2}$ This is especially surprising given that, from a priori reasoning and due to the greater openness of economies, one would most likely have expected the effects of population growth on economic performance to have decreased over time not increased.
} 
The empirical evidence supporting this view is provided in Table 1, which reports our main estimation results. Panel A in the table contains results associated with the period 1960-74, while the panels B and C give results for the period 1975-97. Columns 1, 3 and 5 in Table 1 report results where the dependent variable is respectively the yearly grow $\operatorname{th}^{3}$ in GDP-per-adult, the yearly growth in GDP-per-worker and the yearly change of the employmentto-adult population ratio. Recall that we are defining adults here as individuals aged between 15 and 64. Each of these variables is then regressed on two variables: the yearly growth rate of population aged 15-64 (denoted A-Pop. Gr) and the initial (log) level of GDP-per-adult in the initial year (expressed in US\$) - i.e. GDP-per-capita in either 1960 or $1975 .{ }^{4}$ This specification can be derived from a standard growth model (see e.g. Solow (1956)) when we assume that countries have similar technology and preferences, but differ only with respect to their rates of population growth. In columns 2,4 and 6 of each panel, we add as regressor the countries average investment-to-GDP ratio over the period ${ }^{5}$ and two dummy variables that are meant to capture broad institutional differences across countries. The first dummy variable equals 1 if the country is predominately an Anglo-Saxon country ${ }^{6}$, and the

\footnotetext{
${ }^{3}$ In all cases, the yearly growth rate is calculated as to the average growth rate over the period. In the case of Germany, due to unification, yearly averages are calculated for West-Germany only and are restricted to the period 1975-91 instead of 1975-97. We have exploited longer series for West-Germany, and found our results to be unaffected.

${ }^{4}$ For the 1960-74 sample, we use Barro and Sala-i-Martin measure of GDP-per-capita in 1960 for initial values (See Table 10.1 in Barro Sala-i-Martin (1995)). For the 1975-97 sample, we update this measure using respectively the observed growth in GDP-per-adult and per-worker over the period 1960-74.

${ }^{5}$ The investment-to-GDP ratios are taken from the Heston and Summers data set and include both private and public investments. We chose to use the Heston and Summers' investment ratio to allow our results to be easily compared with the growth regression literature. However, this choice has forced us to calculate the average investment rate over the later period using data only up to 1992.

${ }^{6}$ These are Australia, Canada, New Zealand, the United Kingdom and the United States
} 
second dummy variable equals 1 for the three Scandinavian countries ${ }^{7}$.

The main pattern of results in panels A and B of Table 1 is rather clear. Over the period 1960-74, adult population growth is found to exert only a small and insignificant effect on all three measures of economic performance - GDP-per-adult, GDP-per-worker and employment rate - and, for both output measures, there is strong evidence of convergence (approx. $4 \%$ per year), which is consistent with standard growth theory. The pattern over the 1975-97 is different and more intriguing. First note that the behavior of output-per-adult and output-per-worker diverges in terms of their relationship with adult population growth (denoted A-Pop. Gr.). Second, note that this divergence is entirely due to a change in the behavior of output-per-worker in the second period relative to the first, since the behavior of output-per-adult is rather unchanged. Accordingly, we also see the emergence of a significant positive effect of adult population growth on employment rates over the later period. In effect, our point estimates in panel B suggest that a country with a yearly rate of adult population growth of $1 \%$ greater than the average experienced a poorer growth in output-perworker of approximately $1 \%$ per year. This is actually a huge effect as, when compounded over the 22 years of the sample, it corresponds to a difference of $25 \%$ in labor productivity. It is worth noting that the pattern described above is hardly affected by whether we include dummy variables for AngloSaxon and Scandinavian countries, and whether or not we include average investment rates. Furthermore, it is worth emphasizing that the appearance of a change in both the output-per-worker relationship and the employment rate relationship between the 1960-74 period versus the 1975-97 period are statistically significant. In fact, we tested and could reject at the $5 \%$ level

\footnotetext{
${ }^{7}$ These are Denmark, Norway and Sweden
} 
Table 1: Cross-country Regressions

\begin{tabular}{|c|c|c|c|c|c|c|}
\hline \multirow[t]{2}{*}{ Dep. Var. } & \multicolumn{2}{|c|}{$\% \Delta(Y / A)$} & \multicolumn{2}{|c|}{$\% \Delta(Y / L)$} & \multicolumn{2}{|c|}{$\% \Delta(L / A)$} \\
\hline & $(1)$ & $(2)$ & $(1)$ & $(2)$ & (1) & $(2)$ \\
\hline & \multicolumn{6}{|c|}{ Panel A: 1960-74 } \\
\hline \multirow[t]{2}{*}{ A-Pop. Gr. } & -0.205 & -0.060 & -0.312 & -0.279 & 0.104 & 0.212 \\
\hline & $(0.170)$ & $(0.025)$ & $(0.221)$ & $(0.297)$ & $(0.139)$ & $(0.154)$ \\
\hline \multirow[t]{2}{*}{ Init. $(Y / N)$} & -0.037 & -0.034 & -0.043 & -0.036 & 0.005 & 0.001 \\
\hline & $(0.005)$ & $(0.006)$ & $(0.006)$ & $(0.007)$ & $(0.004)$ & $(0.003)$ \\
\hline I/Y and Dum. & No & Yes & No & Yes & No & Yes \\
\hline \multirow[t]{2}{*}{$R^{2}$} & 0.84 & 0.86 & 0.81 & 0.86 & 0.19 & 0.61 \\
\hline & \multicolumn{6}{|c|}{ Panel B: 1975-97 } \\
\hline \multirow[t]{2}{*}{ A-Pop. Gr. } & -0.363 & -0.288 & -0.989 & -1.217 & 0.617 & 0.918 \\
\hline & $(0.288)$ & $(0.398)$ & $(0.325)$ & $(0.461)$ & $(0.242)$ & $(0.367)$ \\
\hline \multirow[t]{2}{*}{ Init. $(Y / N)$} & -0.023 & -0.024 & -0.019 & -0.019 & -0.003 & -0.005 \\
\hline & $(0.008)$ & $(0.008)$ & $(0.009)$ & $(0.010)$ & $(0.007)$ & $(0.008)$ \\
\hline I/Y and Dum. & No & Yes & No & Yes & No & Yes \\
\hline \multirow[t]{3}{*}{$R^{2}$} & 0.41 & 0.56 & 0.50 & 0.61 & 0.31 & 0.38 \\
\hline & \multicolumn{6}{|c|}{ Panel C:1975-97 } \\
\hline & IV & WLS & IV & WLS & IV & WLS \\
\hline \multirow[t]{2}{*}{ A-Pop. Gr. } & -0.472 & 0.194 & -1.093 & -0.835 & 0.614 & 1.015 \\
\hline & $(0.326)$ & $(0.340)$ & $(0.383)$ & $(0.339)$ & $(0.293)$ & $(0.363)$ \\
\hline \multirow[t]{2}{*}{ Init. $(Y / N)$} & -0.023 & -0.023 & -0.019 & -0.021 & -0.003 & -0.002 \\
\hline & $(0.008)$ & $(0.007)$ & $(0.010)$ & $(0.006)$ & $(0.007)$ & $(0.007)$ \\
\hline I/Y and Dum. & No & No & No & No & No & No \\
\hline$R^{2}$ & & 0.94 & & 0.92 & & 0.58 \\
\hline
\end{tabular}

Note: Standard errors in parenthesis. $Y / A$ : Output-per-adult. $Y / L$ : Output-per-worker. $L / A$ : Employement rate (workers-peradult). 
the hypothesis that the coefficients in these regressions are stable over the two samples.

We also explored the robustness of our results with respect to the inclusion of other variables such as measures of human capital. Although not reported here, we found the patterns described in Table 1 to be robust to controlling for human capital differences across countries as measured either by the average number of years of education or by the school enrollment rates. ${ }^{8}$

Given this rather striking observation with respect to the behavior of GDPper-worker and the employment rate over the period 1975-97 versus the period 1960-74 - especially the increased importance of adult population growth - it is relevant to further explore the robustness of this observation. To this end, in panel $\mathrm{C}$ of Table 1, we report regressions using an instrumental variable (IV) strategy and using weighted least squares (WLS). In Columns 1, 3 and 5 of panel $\mathrm{C}$, we used adult population growth over the period 1960-74 as an instrument for adult population growth over the period 1975-97. This instrumental variable strategy has the attractive feature of countering possible biases due to an endogenous response of population growth - especially immigration - to contemporaneous developments in the economy. As can be seen in panel C, our estimates for the period 1975-97 are essentially unaffected by this instrumental variable strategy suggesting that the endogeneity of adult population growth in unlikely to be an important problem over such a short period. In Columns 2, 4 and 6 of Panel C, we use the square root of active population in 1975 to weight observations. As can be seen, the effect of weighting our observations has again very little effect on our estimates.

\footnotetext{
${ }^{8}$ These omitted results are available from the authors upon request.
} 
Table 2: Cross-country Regressions, Controlling for Age Structure

\begin{tabular}{|c|c|c|c|c|c|c|}
\hline \multirow[t]{2}{*}{ Dep. Var. } & \multicolumn{2}{|c|}{$\% \Delta(Y / A)$} & \multicolumn{2}{|c|}{$\% \Delta(Y / L)$} & \multicolumn{2}{|c|}{$\% \Delta(L / A)$} \\
\hline & (1) & (2) & (1) & (2) & (1) & (2) \\
\hline & \multicolumn{6}{|c|}{ Panel A: 1960-74 } \\
\hline \multirow{2}{*}{ A-Pop. Gr. } & 0.396 & -0.138 & 0.280 & -0.386 & 0.115 & 0.240 \\
\hline & $(0.582)$ & $(0.257)$ & $(0.686)$ & $(0.304)$ & $(0.368)$ & $(0.171)$ \\
\hline \multirow{2}{*}{ Init. $(Y / N)$} & -0.032 & -0.033 & -0.033 & -0.034 & 0.001 & 0.001 \\
\hline & $(0.006)$ & $(0.006)$ & $(0.007)$ & $(0.007)$ & $(0.004)$ & $(0.004)$ \\
\hline \multirow{2}{*}{$\% \Delta \frac{C}{C+A+E}$} & 0.024 & - & 0.027 & - & -0.003 & - \\
\hline & $(0.032)$ & & $(0.037)$ & & $(0.020)$ & \\
\hline \multirow[t]{2}{*}{$\% \Delta \frac{E}{C+A+E}$} & 0.040 & - & 0.054 & - & -0.013 & - \\
\hline & $(0.043)$ & & $(0.050)$ & & $(0.027)$ & \\
\hline \multirow[t]{2}{*}{ C-Pop. Gr } & - & 0.151 & - & 0.130 & - & 0.021 \\
\hline & & $(0.206)$ & & $(0.243)$ & & $(0.136)$ \\
\hline \multirow[t]{2}{*}{ E-Pop. Gr. } & - & 0.645 & - & 0.827 & - & -0.162 \\
\hline & & $(0.471)$ & & $(0.558)$ & & $(0.313)$ \\
\hline \multirow{3}{*}{$\begin{array}{l}\text { I/Y and Dum. } \\
R^{2}\end{array}$} & yes & yes & yes & yes & yes & yes \\
\hline & 0.88 & 0.88 & 0.88 & 0.89 & 0.63 & 0.64 \\
\hline & \multicolumn{6}{|c|}{ Panel B: 1975-97 } \\
\hline \multirow[t]{2}{*}{ A-Pop. Gr. } & -0.322 & -0.253 & -1.208 & -1.240 & 0.875 & 0.973 \\
\hline & $(0.447)$ & $(0.484)$ & $(0.518)$ & $(0.558)$ & $(0.407)$ & $(0.441)$ \\
\hline \multirow[t]{2}{*}{ Init. $(Y / N)$} & -0.024 & -0.024 & -0.021 & -0.021 & -0.003 & -0.003 \\
\hline & $(0.010)$ & $(0.010)$ & $(0.012)$ & $(0.012)$ & $(0.009)$ & $(0.009)$ \\
\hline \multirow{2}{*}{$\% \Delta \frac{C}{c+A+E}$} & -0.004 & - & 0.004 & - & -0.009 & - \\
\hline & $(0.018)$ & & $(0.020)$ & & $(0.016)$ & \\
\hline \multirow{2}{*}{$\% \Delta \frac{E}{C+T+E}$} & -0.003 & - & -0.002 & - & -0.001 & - \\
\hline & $(0.014)$ & & $(0.016)$ & & $(0.013)$ & \\
\hline \multirow[t]{2}{*}{ C-Pop. Gr } & - & -0.030 & - & 0.097 & - & -0.123 \\
\hline & & $(0.290)$ & & $(0.335)$ & & $(0.264)$ \\
\hline \multirow[t]{2}{*}{ E-Pop. Gr. } & - & -0.034 & - & -0.052 & - & -0.019 \\
\hline & & $(0.251)$ & & $(0.289)$ & & $(0.229)$ \\
\hline \multirow{2}{*}{$\begin{array}{l}\mathrm{I} / \mathrm{Y} \text { and Dum. } \\
R^{2}\end{array}$} & yes & yes & yes & yes & yes & yes \\
\hline & 0.56 & 0.56 & 0.62 & 0.61 & 0.40 & 0.40 \\
\hline
\end{tabular}

Note: Standard errors in parenthesis. $Y / A$ : Output-per-adult. $Y / L$ : Output-per-worker. $L / A$ : Employement rate (workers-per-adult) 
Another possibility we want to explore is whether the effects we observed in Table 1 are likely driven by differences in the rate of growth of the adult population or whether instead they may mainly reflect different changes in the age structure of the population. For example, one may expect the adult employment rate to be influenced by changes in the population of children (individuals less that 15) or in the population of elderly (individuals more than 64). To address this issue, we consider two sets of additional regressors that capture changes in the age structure. The first set is composed of (i) the percentage change in the ratio of the child population to the total population (denoted $\% \Delta \frac{C}{C+A+E}$ ), and (ii) the percentage change in the ratio of the elderly population to the total population (denoted $\% \Delta \frac{E}{C+A+E}$ ). The second set is simply the growth rate of the child population (C-Pop. Gr.) and the growth rate of the elderly population (E-Pop. Gr.). The regression results associated with including these additional variables in presented in Table 2 . In all the cases in Table 2 we include in addition to the rate of growth the adult population, the initial level of output-per-adult, the average investment rate over the period and the two dummy variables for the Anglo-Saxon countries and the Scandinavian countries. As can be seen from the table, the inclusion of controls for changes in the age structure of the population does not affect our previous observation regarding the effect of adult population growth. Moreover, and somewhat surprisingly, we do not find the variables capturing changes in the age structure to significantly affect any of the three measures of economic performance in either the 1960-74 period or in the 1975-97 period. Hence, this suggests that the most important demographic factor over this period is likely the change in the working age population.

In summary, results reported in Table 1 and in Table 2 suggest that some- 
thing quite radical has happened over period 1975-75 when compared to the period 1960-74. In particular, since 1975, countries with low adult population growth appear to have been able to increase output-per-adult at the same rate as their higher population growth counterparts, while substantially reducing their labor effort in comparison to the higher population growth countries. Disregarding possible issues related to within-country equity, this seems like a huge success for lower population growth economies relative to higher population growth economies over this period. Our goal is therefore to understand such successes. In particular, we will explore whether these observations can be explained qualitatively and quantitatively within the context of a simple neo-classical model where there is a common diffusion of a new production process, but where the adoption of this new process is endogenous and affected by the growth rate of the working age population.

\section{A Model of the Effects of Population Growth During a Technological Transition}

The results presented in Table 1 and 2 suggest that adult population growth was more important in determining economic outcomes in the 1975-97 period than in the period 1960-74. In light of neo-classical growth theory, it is quite natural to ask whether such observations could simply be the reflection of a technological change that has favored capital accumulation - i.e. has been capital biased - and, accordingly, has been exploited more rapidly by low population growth economies since such economies do not need to constantly use their savings to simply equip new labor market entrants. This is precisely the route that we will follow. To this end, we develop a simple 
growth model where technological change can take two different forms and where households optimally determine their labor supply. We explicitly include a labor supply decision in the model since we want to examine whether such a model can simultaneously explain the behavior of output-per-adult, output-per-worker and employment-per-adult. Moreover, besides allowing for labor-augmenting technological progress as in traditional growth theory, we also allow a radical technological change to take the form of the arrival and dissemination of alternative production process. In particular, we will assume that the new technology exhibits less decreasing returns to capital accumulation than the existing technology. ${ }^{9}$ Finally, note that we have chosen to build our model such that it embeds the Solow growth model as a particular case.

\section{Technology}

We consider an economy where there is one aggregate final output $Y_{t}$ which is produced by competitive firms using a continuum of intermediate goods indexed by $i, i \in[0,1]$ using a constant returns-to-scale technology represented by the following CES production function

$$
Y_{t}=\left(\int_{0}^{1} Y_{i, t}^{\rho} \mathrm{d} i\right)^{\frac{1}{\rho}}, \quad 0 \leqslant \rho \leqslant 1
$$

where $Y_{i, t}$ denotes the quantity of the intermediate good $i$ used in the production of the aggregate good. In each sector, there is again a set of competitive firms, which can produce intermediate goods using a traditional production process which depends on capital $K$ and efficient units of unskilled labor $\theta L$

\footnotetext{
${ }^{9}$ Our model shares similarities with other models of endogenous technological adoption such as those presented in Acemoglu (1998), Basu and Weil (1998), Beaudry and Green (2001), Caselli (1999) and Zeira (1998).
} 
according to the following production function.

$$
Y_{i, t}=K_{i, t}^{\alpha}\left(\theta_{t} L_{i, t}\right)^{1-\alpha}, \quad 0<\alpha<1
$$

Here again, $K_{i, t}$ and $L_{i, t}$ respectively denote the amount of capital and employment used in each sector. Throughout, we will refer to capital generically and interpret it as representing an aggregate of human and physical capital. ${ }^{10}$

In the above sectorial production function, we allow for technological change through growth in $\theta_{t}$ which takes place at an exogenous and constant rate of growth $\nu$. However, we also want to incorporate into the model the possibility of a more radical technological change in the form of the arrival and dissemination of a new production process. To this end, let $i_{t}^{\star}$ denote the fraction of sectors, say $i \in\left[0, i_{t}^{\star}\right]$, which can produce an intermediate good using either the traditional production process given above, or instead can use the following alternative production process which depends on the same factors but exhibits less decreasing returns to capital

$$
\widetilde{Y}_{i, t}=\Phi K_{i, t}^{\beta}\left(\theta_{t} L_{i, t}\right)^{1-\beta}, \quad 0<\alpha<\beta<1
$$

where $\Phi$ may be viewed as the relative total factor productivity of the new technology. We interpret this alternative production process, or alternative form of work organization, as a General Purpose Technology that over time may become applicable to an increasing fractions of sectors. This increased dissemination is then captured by increases in $i_{t}^{\star}$. As already noted, our goal with this model is to illustrate how a change in $i_{t}^{\star}-i$.e. an increased dissemination of a new production process - can lead to different outcomes

\footnotetext{
${ }^{10}$ Since there is a large class of models where an explicitly modeling of human and physical capital leads to a reduced form in which human and physical capital actually act as an aggregate (see e.g. Barro Sala-i-Martin (1995), chapter 4), the approach is not overly restrictive.
} 
across countries even if the dissemination is common to all countries. However, before examining such an issue, it is necessary to first discuss household decisions.

\section{Households}

Households in our model control two decisions: a saving decision and a labor supply decision. Our approach is to assume that households have bounded rationality in the following sense. With regard to their savings decision, households view the environment as sufficiently complex to be satisfied by the simple rule of saving a constant fraction of output. Obviously, behavior very close to this rule can be shown to be optimal in many different environments. However, we prefer here to simply impose such behavior, as is done since Solow (1956) and in Mankiw, Romer and Weil (1992), and thereby bypass the need to justify a particular structure for getting the same outcome. Nonetheless, in the appendix we show a simple case with dynastic linkages where optimizing behavior generates a constant saving rate. With respect to labor supply decisions, we assume that households behave optimally. Our justification for this asymmetric treatment of behavior is that, given the savings decision, the labor supply decision is actually much simpler since it is static and hence makes optimal decision making more likely. The representative household's static problem may then be stated as follows.

$$
\max _{c_{t}, l_{t}} U\left(c_{t}, l_{t}\right)
$$

subject to

$$
c_{t}=(1-s) y_{t}=(1-s)\left(w_{t} l_{t}+r_{t} k_{t}\right)
$$

And the dynamics of capital are given by

$$
(1+\eta)(1+\nu) k_{t+1}=s y_{t}+(1-\delta) k_{t}
$$


where $c_{t}, l_{t}, k_{t}, y_{t}$ represent respectively - in per capita terms - consumption, labor supply, capital and income, $\eta$ denotes the rate of population growth, $s$ the exogenous rate of savings, $\nu$ is the growth rate of $\theta$ and $\delta$ is the rate of capital depreciation. Since we want labor-augmenting technological change to generate balanced growth, we assume the households preferences are represented by

$$
U\left(c_{t}, l_{t}\right)=\log \left(c_{t}\right)+\frac{\psi}{1-\gamma}\left(1-l_{t}\right)^{1-\gamma}
$$

As is well-known from the business cycle literature, these preferences assure that employment remains constant along a balanced growth path generated by labor augmenting technological change. ${ }^{11}$ We share the common view that balanced growth is likely the norm, and find it important to maintain the possibility of balanced growth in our model. Accordingly, we regard the possibility of non-balanced growth induced by the arrival of a new production process, as we allow here, as relevant for infrequent (but possibly important) episodes associated with structural change.

A Walrasian Equilibrium in this setting is a sequence of prices and allocations, such that given prices, allocation maximizes profits (when taking technological choice into account) and maximizes utility (subject the savings behavior), and all markets clear.

\footnotetext{
${ }^{11}$ It should be noted that all our results generalize to the case where preferences are quasi-concave and of the form $U(c, 1-l)=\frac{c^{1-\sigma}}{1-\sigma} v(1-l), 0<\sigma \neq 1$, that is, our results can be generalized to the entire case of preferences consistent with balanced growth.
} 


\section{Equilibrium Analysis}

We now examine the extent to which the Walrasian Equilibrium of the model developed in the previous section can help explain the set of observations discussed in section II. We will begin by a qualitative analysis which focuses on steady state properties of the model. A quantitative analysis which takes account of transitional dynamics will then supplement it and give some insights about the empirical relevance of our model. Our aim is clarify the reasons why economic performance across countries with different rates of growth in working age population may diverge considerably when there is the arrival and dissemination of a new production process. In particular, we want to show that the dissemination of such a technology can cause the behavior of output-per-adult, output-per-worker and employment-per-adult to exhibit the features described in section II. It should be immediately emphasized that in our model population growth affects economic outcomes through a mechanism well known in neo-classical growth theory: population growth reduces the steady state capital-labor ratio because equipping new labor market entrants acts as a drag on capital accumulation.

\section{Qualitative Analysis}

To have a base of comparison, it is useful to first recall how countries with different rates of adult population growth would react in our model to a one time change in $\theta$, or alternatively to a one time shift up in its growth path of $\theta$ - i.e. not a change in its growth rate. ${ }^{12}$ As can be easily verified, a one time shift up in the growth path of $\theta$ causes steady-state output in our model to

\footnotetext{
${ }^{12}$ We consider a one time change in $\theta$, since we will compare it with a one time change in $i^{\star}$.
} 
grow by the same proportion independently of the rate of population growth, and it leaves the employment rates unaffected. Hence, it is fair to say that in our model - as is the case in the Solow growth model - a country's long run adjustment to a one time change in labor augmenting technological progress is independent of its rate of population growth. However, as indicated in the next two propositions, this is not the case for a change in $i^{\star}$. In our model, when technological change takes the form of an increased dissemination of an alternative production process, a country's adjustment depends inherently on its rate of growth of the working age population.

Proposition 1 An increase in $i^{\star}$ will cause the relationship between the steady state value of $\frac{y}{l}$ the rate of population growth to become more negative.

Proposition $1^{13}$ addresses how population growth and technological dissemination interact in our model to determine $y / l$. Otherwise stated, an increase in $i^{\star}$ increases the semi-elasticity of steady state $y / l$ with respect to $\eta .^{14}$ When viewed in this way, the proposition offers a comparative static which can be checked against our observations on output-per-worker. However, to make such a comparison, we need to be willing to infer steady state implications from the empirical results from Table 1. More precisely, such steady state implications of population growth can be readily inferred from

\footnotetext{
${ }^{13}$ Propositions 1 and 2 are readily derived from the steady state conditions of the model. However, in order to save space, the proof of Proposition 1 and 2 are omitted from the paper but are available from the authors upon request.

${ }^{14}$ The exercise performed is to first consider the relationship between steady state outcomes and population growth for the case where $i^{\star}=0$. Denote this relationship as $z\left(\eta, i^{\star}=0\right)$, where $z$ is the $\log$ of $y / l$. Then consider the relationship between steady state outcomes and population growth for the case where $i^{\star}>0$, and denote this relationship as $z\left(\eta, i^{\star}>0\right)$. The proposition tells us that $\frac{\partial z\left(\eta, i^{\star}>0\right)}{\eta} \geq \frac{\partial z\left(\eta, i^{\star}=0\right)}{\eta}$ for all $\eta$
} 
these empirical results by multiplying the estimated effects of population growth by the inverse of the speed of convergence. With this interpretation in mind, proposition 1 indicates that the observed increased importance of population growth on long-run output-per-worker may be the result of the arrival and dissemination of an accumulation-biased technology during the period 1975-97. Proposition 2 follows-up on proposition 1 by examining the model's implication for the sensitivity of the employment rate with respect to population growth.

Proposition 2 An increase in $i^{\star}$ (starting from $i^{\star}=0$ ) causes the emergence of a positive association between the steady state rate of employment $(l / n)$ and the economy's rate of population growth.

Proposition 2 further illustrates that the observations highlighted in section II are the type of effects one should expect if, during the 1975-97 period, there has been the arrival and dissemination of new means of production which favors accumulable factors. In particular, it offers an explanation to the emergence of employment rate differences across industrialized countries which departs quite radically from the dominant view whereby it is predominantly institutionally driven. The explanation the model suggests is that countries with lower rates of population growth have taken greater advantage of new opportunities offered by capital deepening, since they have not needed to use as much of their savings to equip new labor market entrants. Accordingly, they have taken some of the gains associated with this change in terms of decreased labor supply. ${ }^{15}$ The fact that proposition 2 indicates that a technological change can affect steady state employment-per-adult

\footnotetext{
${ }^{15}$ Some readers may immediately object to such an interpretation claiming that it is increased unemployment and not increased leisure that characterizes low employment rate
} 
may appear surprising given that the class of preferences we assume implies that long run labor supply is invariant to labor augmenting technological progress. However, it is precisely because of this property that labor supply will be affected by a radical technological change. One way to see this is to note that labor supply is a function of the fraction of income derived by capital. Since this fraction increases in our model as an economy adopts the new technology, long run labor supply will decrease. In other words, the increased capital intensity allowed by the arrival of the new technology causes a particularly strong wealth effect in low population growth economies which is not offset by a sufficiently strong substitution effect. In contrast, the strength of the wealth effect is reduced in high population growth economies since capital deepening is less pronounced.

In order to complete the picture described in section II, we need to ask whether our model could also generate the pattern we observed for outputper-capita: Can an increase in $i^{\star}$ cause an increase in the sensitivity (semielasticity) of $y / \theta l$ with respect to $\eta$ while simultaneously not causing an increase in the sensitivity of $y / \theta$ with respect to $\eta$ ? The answer to this question is clearly positive due to the offsetting effects described in propositions 1 and 2 . In fact, an increase in $i^{\star}$ in our model can be associated with either an increase or a decrease in the sensitivity of $y$ with respect to $\eta$. The only restrictions imposed by the model on this relationship are (i) that the effect of population growth on output-per-adult be non-positive and (ii) that it be no greater in magnitude than that observed for output-per-worker.

countries. However, it can be easily verified that much of the differences in workloads across industrial countries are due to differences in participation rates and differences in hours worked-per-employed worked. This is not to say that unemployment is unimportant. Instead, it is meant to point out that there are important differences in employment rates across countries that are not simply reflections of unemployment rate differences. 


\section{- Figure 1 About Here -}

To help visualize the extent to which $i^{\star}>0$ can cause the steady state behavior of $y$ (output-per-adult) and $y / l$ (output-per-worker) to diverge, both within and across economies, we have graphed both $y / \theta l$ and $y / \theta$ as a function of $k / \theta$ in Figure 1. Furthermore, we superimpose the steady state condition between $y / \theta$ and $k / \theta$, given by

$$
\frac{y}{\theta}=\frac{(1+\eta)(1+\nu)-(1-\delta)}{s} \frac{k}{\theta}
$$

The relationships relating $(y / \theta l)$ and $(y / \theta)$ with $(k / \theta)$ are different due to the endogenous labor supply decision. The figure is drawn for the special case where $\gamma=0$, that is, the case where leisure enters utility linearly. Although this is an extreme case, its clear implications make it perfect for illustration. Note that there is a minimal level of capital-per-adult before which the presence of the alternative technology will have an effect and hence, in this region, $(y / \theta l)$ and $(y / \theta)$ behave identically. This minimum level of effective capital-per-adult is denoted $(k / \theta)^{m}$. Once beyond $(k / \theta)^{m}$, the behavior of $(y / \theta l)$ and $(y / \theta)$ diverge. In particular, until we reach $(k \theta)^{s},(y / \theta l)$ increases in a convex fashion while $(y / \theta)$ remains constant. The level $(k / \theta)^{s}$ corresponds precisely to the level of capital-per-adult which assures that all sectors $i \leq i^{\star}$ have fully adopted the more capital intensive technology. When capital intensity moves beyond $(k / \theta)^{s}$, output-per-capita starts increasing anew.

The points $(k / \theta)^{\eta_{0}},(y / \theta)^{\eta_{0}}$ and $(y / \theta l)^{\eta_{0}}$ on the graph correspond to the steady state levels for an economy with population growth $\eta_{0}$. Using the steady state relationship between $(y / \theta)$ and $(k / \theta)$, we can easily conduct comparative static exercise for $\eta$ around $\eta_{0}$. In particular, a reduction in population 
growth corresponds to a flattening of the steady state relationship and hence an increase in $(k / \theta)$. The interesting aspect is to note that the reduction in population growth will be associated in the steady state with an increase in labor productivity but no change in output-per-capita. Moreover, the change in labor productivity due to the change in population growth will be much larger in this case that what would have been observed if $i^{\star}=0$. In this respect, Figure 1 captures most of the content of our qualitative exercise.

\section{Quantitative Analysis}

Our theoretical analysis suggests that the patterns highlighted in section II may reflect the interaction between adult population growth and the dissemination of a new production process. Our main objective in this section is to explore the plausibility of this explanation by examining whether our model, once quantified, can in effect reproduce the type of regressions we presented in the empirical part. To this end, we begin by parameterizing our model, estimating the unknown parameters and then evaluating whether it can reasonably reproduce the regression results.

Since the model is to be evaluated on quantitative grounds, we have to specify functional forms for the utility function. We therefore assumed that it takes the following form

$$
U(c, l)=\log (c)-\psi l
$$

thereby imposing $\gamma=0 .{ }^{16}$ Note that the parameter $\psi$ is essentially irrelevant for our purpose as it provides no information on the relationship between rates of growth. Therefore, we calibrate it such that in the 1960-74 steady

\footnotetext{
${ }^{16}$ We conducted the estimation trying different values for $\gamma$, which did not yield significative differences in the results.
} 
state, employment is normalized to 1 . The parameter $\rho$ ruling the elasticity of substitution between intermediate goods in the production of the final good is set to 1 , as we did not find any major implication of this parameter on our results. The parameter $\Phi$ is first set to a value such that in 1975 , the US economy would be indifferent between using the old or the new means of production. ${ }^{17}$ Then, to start the adoption process, we increase $\Phi$ by a factor of $(1+\varphi)$ and assume that the new technology becomes available in all sector (that is, $i^{\star}=1$ ).

In the lines of Mankiw, Romer and Weil (1992), the depreciation rate, $\delta$, is set at an annual rate of $6 \%$. The rate of growth of the exogenous technological progress, $\nu$, is set at $2.5 \%$ per year, which implies a rate of growth of total factor productivity between 1 and $1.5 \%$ per year. The saving rate, assumed to be identical across all countries, is set at $20 \%$. The other parameters, $\Theta=\{\alpha, \beta, \varphi\}$ are estimated.

Our estimation strategy is based on a moment estimation method. The vector of parameters $\Theta$ is obtained in order to minimize the discrepancy between a set of moments obtained from the data and those obtained using the model. We therefore select the deep parameters of the model in order to replicate the set of regressions reported in section II for output-per-capita and outputper-worker. ${ }^{18}$ More specifically, $\alpha$ is selected such that the model, when simulated on the 1960-1974 period, minimizes the discrepancy between the

${ }^{17}$ This implies a initial value of $\Phi$ given by

$$
\Phi=\left(\frac{\alpha}{\beta}\right)^{\beta}\left(\frac{1-\alpha}{1-\beta}\right)^{1-\beta}\left(\frac{k_{U S, 1975}}{l_{U S, 1975}}\right)^{\alpha-\beta}
$$

${ }^{18}$ The employment-per-capita regression may then be trivially obtained from the first two regressions. 
regression displayed in column 1 of panel $\mathrm{A}$ in Table 1 and the same regression using data obtained from the model simulation. $\beta$ and $\varphi$ are set such that the model, when simulated on the 1975-1997 period, replicates as close as possible the regression displayed in column 1 and 3 of panel B in Table 1. Hence, our world economy will consist of the 18 countries $(N=18)$ considered in the empirical study (see section II). The initial distribution of revenues - in terms of output-per-capita - and labor force growth $\left\{\eta_{i} ; i=1 \ldots, N\right\}$ - are taken from the data. Table 3 reports the results. ${ }^{19}$

Table 3: Estimation results

\begin{tabular}{ccc}
\hline \hline$\alpha$ & $\beta$ & $\varphi$ \\
\hline 0.513199 & 0.789095 & 0.242384 \\
\hline \hline
\end{tabular}

As indicated in Table 3, we obtain a value for $\alpha$ of 0.513199 when trying to replicate the observations over the 1960-74 period assuming $i^{\star}=0$. In order to see the fit of the model over this early period, Table 4 compares the regressions results implied by the model when $\alpha=0.513199$ with those observed for output-per-adult prior of 1975. As can be seen in this table, with $i^{\star}=0$ (which corresponds to the standard Solow growth model) the model is capable of replicating almost exactly the effect of population growth on the rate of growth of output-per-adult. Note that in this case (when $i^{\star}=0$ ), the model does not generate any differences across countries in employment rates and therefore the predictions of the model for the behavior

\footnotetext{
${ }^{19}$ For the 1960-1974 experiment, capital is assumed to be in steady state in 1960 in the US economy. The stock of physical capital in the other economies are obtained from the income distribution in 1960 and using the production function as
}

$$
k_{i, 1960}=k_{U S, 1960} \times\left(\frac{y_{i, 1960}}{y_{U S, 1960}}\right)^{\frac{1}{\alpha}}
$$


of output-per-worker are identical as those for output-per-adult.

Table 4: Goodness of fit: 1960-1975 $(\Delta(Y / N)$ regression $)$

\begin{tabular}{lcc}
\hline \hline & Data & Model \\
\hline$\eta$ & -0.205 & -0.205 \\
$(Y / N)_{0}$ & -0.037 & -0.042 \\
\hline$R^{2}$ & 0.84 & 0.99 \\
\hline \hline
\end{tabular}

The second important observation to take from Table 3 is that our estimate of $\beta$, which governs the importance of accumulable factors in the new technology, is 0.78. Since our estimate of $\beta$ is higher than that for $\alpha$, this provides initial support for the view that the patterns highlighted in the empirical section may reflect the arrival of new means of production that exhibit less diminishing returns to factors that can be accumulated. ${ }^{20}$ In order to gauge the empirical relevance of the model, Table 5 compares the regression coefficients obtained from the data and those implied by the model for the 1975-1997 period. As can be seen from this table, the model replicates remarkably well the population growth effects for all three measures of economic performance. The model can also account for the convergence process in terms of output-per-adult, but slightly underestimate the speed of convergence for output-per-worker. Consequently, the model tends to overestimate the speed of convergence for employment-per-adult. However, in both these latter cases, the model's predicted speeds of convergence are well within the estimated confidence intervals for their empirical counterparts. This set of results therefore indicates that the interaction between population growth and the dissemination of a new means of production can quantitatively account for the type of changing pattern we observed in section II.

\footnotetext{
${ }^{20}$ Note that this result was obtained without imposing $\beta>\alpha$ during the estimation.
} 
Table 5: Goodness of fit: 1975-1997

\begin{tabular}{lcccccc}
\hline \hline & \multicolumn{2}{c}{$\Delta(Y / N)$} & \multicolumn{2}{c}{$\Delta(Y / L)$} & \multicolumn{2}{c}{$\Delta(L / N)$} \\
\cline { 2 - 7 } & Data & Model & Data & Model & Data & Model \\
\hline$\eta$ & -0.363 & -0.362 & -0.989 & -0.989 & 0.617 & 0.626 \\
$(Y / N)_{0}$ & -0.023 & -0.019 & -0.019 & -0.011 & -0.003 & -0.010 \\
\hline$R^{2}$ & 0.41 & 0.62 & 0.50 & 0.83 & 0.31 & 0.36 \\
\hline \hline
\end{tabular}

In order to illustrate the mechanisms at work in the model, Figure 2 reports the dynamics of output per adult and output per worker for two different economies as they gradually adopt the new technology. The first economy we consider is representative of a low population growth economy as we set its population growth to zero - i.e. $\eta=0$. The second economy is representative of a high population growth economy as we set $\eta=2 \%$.

\section{- Figure 2 About Here -}

The upper-left panel of the figure reports the dynamics of output-per-capita - expressed in logarithm and normalized to 1 in the initial period — for both economies. We start the economies below their steady states and introduce the new technology such that initially it is not used. The upper-right panel corresponds to the same experiment but now follows the dynamics of outputper-worker - also expressed in logarithm and normalized to 1 in the initial period. As can be seen from the graphs, in the earlier periods of the dynamics, both output-per-capita and output-per-worker evolve along the same path in both economies. But after 3 periods of time, the constant population economy starts adopting the new technology. This capital deepening allows this economy to gain in terms of labor productivity and simultaneously reduce 
its work effort, keeping output-per-capita constant. In contrast, the growing population economy has to wait 2 additional periods before starting this process. This translates into divergent behavior in labor productivity that can be read on the upper-right panel of the graph. This is also confirmed by the lower-left panel of the graph that reports the log-difference of outputper-capita (and output-per-worker) between the two economies. ${ }^{21}$ As soon as an economy reaches the capital-labor ratio required to begin to profitably implement the new technology, output-per-worker and output-per-capita exhibit totally different dynamics. Indeed, as can be seen from the lowerleft panel of the graph, the differences between the two economies reduces to zero in terms of output-per-capita during the adoption phase, while this difference is magnified in terms of output-per-worker. Note that it is this difference which explains why the model can account for the type of empirical regressions we obtained in section II. As a last information, we report in the lower-right panel of Figure 2, the capital share implied by the model. Recall that the capital share here is meant to represent the combined share of both human and physical capital. The implications of the dissemination of the new technology is again seen to be quite large in this type of model, as the capital share can differ between countries by an amount of 10 percentage points during the transition phase.

\footnotetext{
${ }^{21}$ This difference is computed as

$$
\log \left(x_{t}^{\eta=0} / x_{0}^{\eta=0}\right)-\log \left(x_{t}^{\eta=0.02} / x_{0}^{\eta=0.02}\right)
$$

for $x$ denoting alternatively output-per-capita and output-per-worker.
} 


\section{Conclusion}

Over the last quarter of the $\mathrm{XX}^{\text {th }}$ century, economic performance across major industrialized countries have differed considerably, both in terms of output-per-worker and employment-per-capita. More to the point, we have presented empirical evidence suggesting an important change in nature of the relationships between economic outcomes and the dynamics of population over the period 1975-97 versus the period 1960-1975. The object of this paper has been to use these observations to shed light on both the nature of recent technological change and on the reasons for why countries have adjusted differently to these changes. To this end, we have extended a Solow-type growth model in two directions. First, we introduced the possibility of radical technological change in the form of the dissemination of an alternative means of production which displays less diminishing returns to factors that can be accumulated. Secondly, we endowed households with neo-classical preferences between consumption and leisure. We then used the model to illustrate why a major technological change, when arriving in the form of an alternative production process, can lead countries to adjust differently simply due to differences in rates of population growth. We have shown that the model can explain both the qualitative features of the data as well as quantitatively replicate the observed changes in importance of population growth in the cross-country regressions. We therefore believe that differences in adult population growth, due to is interaction with a major technological change, may be an important (and previously neglected) element for understanding the differential economic experiences of industrialized countries since the mid-seventies. 


\section{References}

Acemoglu, Daron (1999), Changes in Unemployment and Wage Inequality:

An Alternative Theory and Some Evidence, American Economic Review 89, $1259-1278$.

Barro, Robert and Xavier Sala-i-Martin (1995), Economic Growth, MIT Press, Cambridge, MA.

Basu, Susanto and David Weil (1998), Appropriate Technology and Growth, Quarterly Journal of Economics 113, 1025-54.

Beaudry, Paul and David Green (2002), Population Growth, Technological Adoption and Economic Outcomes, Review of Economic Dynamics 5, 749775 .

Bresnahan, Timothy and Manuel Trajtenberg (1995), General Purpose Technologies: Engines of Growth?, Journal of Econometrics 65, 83-108.

Caselli, Francesco (1999), Technological Revolutions, American Economic Review 89, 78-102.

Mankiw, Gregory, David Romer and David Weil (1992), A Contribution to the Empirics of Economic Growth, Quarterly Journal of Economics 10\%, 407-437.

Solow, Robert (1956), A Contribution to the Theory of Economic Growth, Quarterly Journal of Economics 70, 65-94.

Zeira, Joseph (1998), Workers, Machines and Economic Growth, Quarterly Journal of Economics 113, 1091-1118. 


\section{A A Dynastic version of the model}

In this section, we consider a dynastic version of the model that rationalizes the constant savings rate assumption used in the text.

\section{Individual behaviors}

In each and every period $t$, a cohort of size $N_{t}$ of new household is born. The size of each cohort is assumed to evolve as

$$
N_{t}=(1+\eta) N_{t-1} \text { with } \eta>0
$$

Each household lives for one period. The individual takes decisions on labor and consumption/savings plans, with savings directed as a bequest towards the next generation. Preferences are represented by a utility function of the form

$$
u\left(c_{t}, h_{t}, b_{t+1}\right)=\log \left(c_{t}\right)+v\left(\ell_{t}\right)+\rho \log \left(b_{t+1}\right)
$$

where $c_{t}, \ell_{t}$ and $b_{t+1}$ respectively denote consumption, leisure and the bequest left to the next generation. $\rho>0$ is the weight attached to the bequest motive. $v($.$) is an increasing and concave function that takes the form$

$$
v\left(\ell_{t}\right)= \begin{cases}\frac{\psi}{1-\gamma}\left(\ell_{t}^{1-\gamma}-1\right) & \text { if } \gamma \in \mathbb{R}_{+} \backslash\{1\} \\ \psi \log \left(\ell_{t}\right) & \text { if } \gamma=1\end{cases}
$$

At the begin of a period, each household receives their share of bequests left by previous generation, $\frac{b_{t}}{1+\eta}$, and supplies her labor $h_{t}$ on the labor market at rate $w_{t}$. These revenues from productive market activities are then used to purchase consumption goods, $c_{t}$ and saves an amount $s_{t}$. Therefore she faces a budget constraint of the form

$$
c_{t}+\frac{b_{t+1}}{1+r_{t+1}}=w_{t} h_{t}+\frac{b_{t}}{1+\eta}
$$


Furthermore, the households is endowed with one unit of time. Maximizing the utility function with respect to $c_{t}, \ell_{t}=1-h_{t}$ and $b_{t+1}$, subject to (A.4), yields the following labor supply behavior

$$
v^{\prime}\left(1-h_{t}\right)=\frac{w_{t}}{c_{t}}
$$

and the following decision rules for consumption, $c_{t}$, and the bequest, $b_{t+1}$

$$
\begin{aligned}
c_{t} & =\frac{1}{1+\rho}\left(w_{t} h_{t}+\frac{b_{t}}{1+\eta}\right) \\
b_{t+1} & =\frac{\rho\left(1+r_{t+1}\right)}{1+\rho}\left(w_{t} h_{t}+\frac{b_{t}}{1+\eta}\right)
\end{aligned}
$$

We finally obtain savings as

$$
s_{t}=w_{t} h_{t}+\frac{b_{t}}{1+\eta}-c_{t}=\frac{\rho}{1+\rho}\left(w_{t} h_{t}+\frac{b_{t}}{1+\eta}\right)
$$

\section{Closing the model}

Noting that next period's capital stock corresponds to total savings in this economy, we have that

$$
K_{t+1}=N_{t} s_{t}=\frac{\rho}{1+\rho}\left(w_{t} N_{t} h_{t}+N_{t} \frac{b_{t}}{1+\eta}\right)=\frac{1}{1+\rho}\left(w_{t} L_{t}+N_{t-1} b_{t}\right)
$$

Furthermore, since all savings is in the form of bequests

$$
N_{t} b_{t+1}=N_{t}\left(1+r_{t+1}\right) s_{t}=\left(1+r_{t+1}\right) K_{t+1}
$$

and hence

$$
K_{t+1}=\frac{\rho}{1+\rho}\left(w_{t} L_{t}+\left(1+r_{t}\right) K_{t}\right)
$$

Assuming factors are paid their marginal product and the technology satisfies constant returns to scale, we have

$$
K_{t+1}=\frac{\rho}{1+\rho}\left(Y_{t}+(1-\delta) K_{t}\right)=s Y_{t}+\mu K_{t}
$$

Hence the law of motion of capital is essentially the same as the one the text, and therefore all our propositions apply to this dynastic version of the model. 